\title{
Entre a Democracia e a Era do Big Data: às vestes do Constitucionalismo Garantista
}

\author{
Between Democracy and The Age of Big Date: to the legends of \\ Constitutionalism Garantist
}

\begin{abstract}
Alfredo Copetti Neto ${ }^{1}$
Caio Coêlho de Oliveira ${ }^{2}$

Karoline França Bastos Cunha ${ }^{3}$

\section{RESUMO}

Para além das concepções teóricas de democracia vinculadas à sua consolidação como organização do Estado, a questão que esse trabalho ressalta é a importância de analisar também a sua transformação e instabilidade, sob o risco de que todo o seu processo de construção e de aprimoramento possa ser desprezado. Assim, pretende-se, com base na concepção de Democracia Constitucional, analisar criticamente os desafios do sistema democrático face ao sistema de big data e o campo das inovações tecnológicas, ora como uma alternativa para o seu aprimoramento representando de fato legítima saída para aperfeiçoamento da democracia representativa, ora como ameaça a ausência de construção de consensos face a ausência de controle - possibilitando um enfrentamento ao processo de manutenção do sistema democrático enquanto forma garantista de Estado.
\end{abstract}

\section{PALAVRAS-CHAVE:}

Democracia, Big Data, Legitimidade, Garantismo, Constitucionalismo.

\begin{abstract}
Beyond the theoretical conceptions of democracy linked to its consolidation as an organization of the State, the question that this work emphasizes is the importance of also analyzing its transformation and instability, under the risk that its entire process of construction and improvement may be despised Thus, it is intended, based on the conception of Constitutional Democracy, to critically analyze the challenges of the democratic system vis-a-vis the big data system and the field of technological innovations, or as an alternative for its improvement,
\end{abstract}

\footnotetext{
${ }^{1}$ Pós-doutor em Direito pela Universidade do Vale do Rio dos Sinos. Professor Titular do Programa de PósGraduação (Mestrado) em Direito da UNIFG. Coordenador do Núcleo de Estudos de Direito, Economia e Instituições. Membro do Garantismo Brasil.

${ }^{2}$ Mestre em Direito pelo Programa de Pós-Graduação Strictu Sensu do Centro Universitário Guanambi (UNIFG). Bolsista FAPESB. Pesquisador do Núcleo de Estudos de Direito, Economia e Instituições (NEDEI). Membro do Garantismo Brasil.

${ }^{3}$ Mestre em Direito pelo Programa de Pós-Graduação Strictu Sensu do Centro Universitário Guanambi (UNIFG). Pesquisadora do Núcleo de Estudos de Direito, Economia e Instituições (NEDEI). Membro do Garantismo Brasil.
} 
representing in fact legitimate exit for the improvement of the representative democracy, or as a threat to the absence of consensus building in the absence of control - enabling a confrontation with the process of maintaining the democratic system as a state guarantor form.

\section{KEYWORDS:}

Democracy, Big Data, Legitimacy, Garantism, Constitutionalism.

\section{INTRODUÇÃO}

Partindo da concepção de que a democracia é um sistema de governo que ao longo do tempo fora edificado a partir de conquistas envolvendo percepções políticas, sociológicas e filosóficas, e, que por sua vez é um sistema orgânico em contínua transformação, busca-se por meio deste compreender as múltiplas concepções teóricas e, sobretudo compreender os desafios que ela enfrenta na sociedade contemporânea. A democracia que vem sendo desenvolvida ao longo de séculos encontra-se diante de grandes ameaças ao seu modelo organizacional, assim podemos observar as grandes transformações do século XX, da sua queda face aos governos autoritários e também da sua ampliação e múltiplas modelagens após as grandes guerras. A partir dessas observações compreendemos que estamos diante um novo momento de testes da estabilidade democrática, seja no Brasil ou no mundo, sobretudo com o avanço das tecnologias da informação e suas contínuas imbricações nas formas de comunicação e mobilização sóciopolítica.

A Era Digital em conjunto com as múltiplas inovações no campo técnico científico apresenta-nos uma nova experiência para a humanidade, seja pela sua capacidade de conexão de sujeitos ou através das mobilizações de seguimentos que antes não desempenhavam influência no processo de construção democrático. A partir da observação desses processos pretende-se aqui, por meio da reflexão e da revisão bibliográfica de teóricos que dedicam sua vida ao estudo do processo de surgimento, transformação e decadência do sistema democrático, compreender o avançar desses processos de reconfiguração, analisando também as influências que podem exercer na constituição de um sistema político, avaliando suas múltiplas análises de 
efetividade, transformação e aprimoramento em face de sua organização enquanto via de organização do Estado.

Compreendemos que o enfraquecimento do sistema democrático iniciou-se a partir do momento em que não fora capaz de entregar aos cidadãos tudo aquilo que se almejava no campo da ampliação dos direitos sociais mínimos; ou, das contínuas falhas que maculam a imagem do sistema democrático através da deslegitimação do modelo representativo, reascendendo o debate sobre a necessidade de ampliação do sistema de uma democracia direta algo completamente difícil de executar em uma sociedade complexa porém contínuo objeto de análise. Para tal faremos uma breve análise da influência que a ampliação do sistema de comunicação se deu na contemporaneidade, sobretudo a interferência em resultados, organizações, bases políticas no processo de politização dos cidadãos, especialmente a disposição de interlocução destes sujeitos na rede de Big Data, que geraram transformações complexas no campo político, contribuições estas que podem representar uma ameaça ao sistema democrático quando esteja sob as mãos de grupos com interesses antidemocráticos.

Para tal pretende-se responder ao seguinte questionamento: até que ponto o sistema de Big Data influencia no processo de construção da democracia e como transformá-lo em uma ferramenta da sua ampliação? Objetivando demonstrar que os efeitos da revolução tecnológica remete a necessidade de importantes transformações no campo jurídico, resguardando a necessidade das regras do jogo democrático como também uma atualização das diretrizes que norteiam a construção de uma democracia constitucional garantista apta a resolver os desafios da atualização democrática, assegurando a sua vertente garantista na busca de impossibilitar o surgimento de um sistema incapaz de assegurar direitos.

\section{BOBBIO E AS FRAGILIDADES DO SISTEMA DEMOCRÁTICO}

Para além do seu processo de transformação histórico, desde a sua compreensão epistêmica que transcende a edificação da democracia enquanto sistema de organização do Estado, seu processo de evolução desde a polis grega, aos significativos avanços deixados pelas compreensões dos contratualistas, passando pelo movimento da estruturação do Estado de 
Direito e suas múltiplas vertentes até a chegada ao Estado Democrático de Direito, consagrado pelas múltiplas Constituições positivadas mundo a fora, representando o maior modelo adotado pelos Estados Nações da contemporaneidade e ao mesmo tempo objeto de violações e fragilização quando diante de tentativas autoritárias ou sob o avanço de um sistema liberal que desdenha dos pilares democráticos.

Neste campo temos o legado de Norberto Bobbio (1909-2004), que ocupa lugar singular nas discussões sobre o processo de construção e aprimoramento do sistema democrático, sobretudo nas explanações que envolvem a fragilidade enquanto sistema, servindo de base teórica para as críticas teóricas, sendo um importante fomentador de problematizações buscando aperfeiçoar o sistema democrático. O jusfilósofo deixou seu legado na estruturação de importantes campos do conhecimento, sobretudo na construção de uma Teoria do Estado, no campo do direito e da ciência política, ganhando importante espaço ao defender o sistema jurídico como fundamento básico para edificação de um sistema democrático. Na edição de "O futuro da democracia: uma defesa das regras do jogo" (BOBBIO, 1995), o autor teve sua contribuição nas lutas políticas de combate aos governos autoritários do século XX exercendo influência política, sobretudo no campo da defesa do resgate das instituições democráticas.

A obra fora escrita no contexto da Guerra Fria, no entanto reeditada e revisada nos anos seguintes. Nesse aspecto o autor acompanhou a emergência de um conjunto de Estados que adotaram o modelo democrático após anos de convivência com sistemas totalitários. A obra pretende não trazer uma visão futurologista, mas aporta-se em uma acurada análise crítica das experiências democráticas vivenciadas até então, como também apontando eixos estratégicos passíveis de revisão para evitar possíveis rompimentos democráticos. Ressalta que a história é imprevisível, porém sinaliza os caminhos para o fortalecimento democrático, uma vez que ele considera o sistema democrático como frágil - não de forma ingênua, mas sim estratégica porém necessário, a partir da sociedade internacionalmente globalizada como fora projetada no final do século. Contexto no qual a dissolução do conflito entre liberais e comunistas, diante o processo de esfacelamento dos ditos regimes comunistas.

Em suas noções introdutórias de democracia, delimita a sua constituição a partir da antítese aos governos autoritários, ou seja, caracteriza iniciando a edificação de um conjunto de regras mínimas as quais atribui características de regras primárias ou fundamentais que delineiam a atuação daqueles que por ventura venham a representar o poder, de forma que estas 
estejam conexas com o potencial de representação daqueles que o elegeram coletivamente. Porém para tal função não se limita a uma mera escolha ou concessão de poder, mas reconheça o potencial de divergência e respeito àqueles que não foram escolhidos. Para tal Bobbio delimita da seguinte forma:

\begin{abstract}
Para que se realize esta condição, é necessário que aos chamados a decidir sejam garantidos os assim denominados direitos de liberdade, de opinião, de expressão das próprias opiniões, de reunião, de associação etc. - os direitos à base dos quais nasceu o Estado liberal e foi construída a doutrina do Estado de direito em sentido forte; isto é, do Estado que não apenas exerce o poder sub lege, mas o exerce dentro de limites derivados do reconhecimento constitucional dos direitos "invioláveis" dos indivíduos. Seja qual for o fundamento filosófico destes direitos, eles são o pressuposto necessário para o correto funcionamento dos próprios mecanismos predominantemente procedimentais que caracteriza um regime democrático. (BOBBIO, 1984, p. 38).
\end{abstract}

O autor oferece as principais características estruturais da concepção de democracia que vieram a marcar sua conceituação. Fortemente baseada na capacidade de que uma ordem democrática consiste sintetize dos consensos de forma que aqueles que por ventura estejam diante o dissenso não sejam subjugados com a imposição da força, tal perspectiva se contrapõe a concepção vulgar de que democracia consiste na construção de unanimidade ou tão somente a construção de maioria, sobretudo porque para Bobbio a sociedade consiste em uma entidade cuja pluralidade de sujeitos e pensamentos que na democracia moderna encontram sua forma de estruturação na democracia representativa, pautada na soberania popular transferida através do sufrágio, que estabelecerão as composições dos parlamentos.

É a partir dessa concepção que Bobbio prossegue apontando os problemas emergentes da democracia representativa e também alguns aspectos que acabam por impactar no processo de consolidação do sistema democrático tornando-o frágil. Elenca que as transformações iniciam com a capacidade de distribuição do poder, passando pelo potencial de representação, o qual por sua vez encontrará entraves no seu processo de execução, que por vezes acabará prevalecendo à manutenção das velhas oligarquias que detinham o poder, além da importância de que os grupos que forem representar não estejam limitados tão somente a um corporativismo social, mas o todo daqueles que compõe a sociedade. Dá prosseguimento à sua análise no campo da ciência política criticando a persistência da presença de oligarquias políticas, eliminação da influência dos "poderes invisíveis" (milícias, gangues, máfia, instituições que não se submetem ao crivo da transparência institucional), a ausência de uma formação capaz de educar os sujeitos para condição de cidadão para o exercício da prática democrática. 
Nessa dinâmica prossegue sua análise tecendo uma crítica à apatia política emergente da não participação, sobretudo quando vinculada à abstenção da participação nos processos de decisão eleitoral. Dá seguimento a uma breve explanação sobre o governo exercido com um excesso de tecnicismo impossibilitando a participação dos cidadãos comuns, acabando por inviabilizar a proposição de uma participação cidadã. Além disso, aporta-se na crítica ao excesso de burocracia que acaba por promover um baixo rendimento das promessas mínimas sustentadas pelo estado democrático. Tal fenômeno é analisado como face da construção contemporânea da vivencia democrática como elucidam os pesquisadores:

\begin{abstract}
A democracia contemporânea pressupõe uma nova relação do sujeito com o ambiente político e, consequentemente, exige desnudá-lo das relações de poder no meio social. Uma visão sóbria da relação entre democracia e direitos fundamentais demanda o reconhecimento do dissenso que contamina o seio social e também demanda reconhecer que, muitas vezes, existirão conflitos entre interesses e mesmo conflitos entre direitos fundamentais. (ALVES; OLIVEIRA; DINIZ, 2016, p.51).
\end{abstract}

O procedimento construtivo é uma das formas de mensurar a qualidade e a intensidade do sistema democrático, também podem ser auferidos pelo seu procedimento de construção das deliberações e a sua efetividade. Uma democracia é efetiva não somente quando os sujeitos são capazes de deliberar na escolha daqueles que serão porta vozes do poder, mas também a intensidade da sua participação e discussão no campo das deliberações políticas. Esse processo de participação é por vezes questionado pelos teóricos e sujeitos políticos.

Tomando a democracia antiga como expressão do modelo de democracia direta, no qual todos aqueles considerados cidadãos podiam exercer seu direito de liberdade através do sufrágio, à democracia contemporânea tem a democracia representativa como mecanismo deliberativo.

Nessa dinâmica, teóricos continuamente questionam sobre o potencial de desenvolvimento de tecnologias capazes de promover a ampliação da participação dos processos deliberativos, seja no campo de construção legal ou nas demais tomadas de decisão do Estado. Objeto de reflexão que pode colocar em risco o próprio sistema democrático uma vez que uma boa democracia não consiste em somente deliberar, mas está vinculada a todo um sistema de normas de direitos e garantias fundamentais. Outro aspecto consiste na ausência de segurança desse mundo digital conforme análise no tópico seguinte: 
decretos, expedir regulamentos, nomear, demitir, administrar ou exercitar toda aquela massa de poderes e funções sem as quais a máquina do poder e do governo fica paralisada ou atravancada." (BONAVIDES, 2002, P.26).

Os limites, da democracia representativa, portanto não podem ser compreendidos tão somente na mera vinculação do sufrágio, exigindo um processo contínuo da participação e aprimoramento dos instrumentos democráticos da oitiva dos representados e representados. Portanto o processo de construção da representatividade democrática deve ser um processo contínuo, porém que tem a sua finalidade na construção e na efetividade dos instrumentos legais elaborados. A democracia direta não é compatível para o grau de complexidade das organizações sociais da contemporaneidade justamente pelo fato de que suas bases estão limitadas, portanto a representação é o recurso, ou melhor, a alternativa viável para assegurar o processo construtivo como melhor base legislativa.

\section{BIG DATA - O NOVO PODER DE ORGANIZAÇÃo E PARTICIPAÇÃO DOS ESPAÇOS DEMOCRÁTICOS}

O crescimento e a importância das tecnologias da informação revolucionaram a sociedade contemporânea, redesenhando todos os espaços de vivencias, como a dinâmica econômica, as relações de interação social, a divulgação e produção do campo científico, não diferente alcançou o campo da ciência política exercendo por sua vez novas transformações no campo jurídico normativo. Aqui se insere justamente a necessidade do direito antever o seu potencial de influência nesse mundo que fora objeto de regulamentação jurídica como principal desafio da contemporaneidade. Coube ao direito não mais normatizar o plano físico, desbravando também o plano digital.

Nesse contexto surge o desafio de compreender e estabelecer as dinâmicas jurídicas desse campo de interação e intensificação das relações. A ausência de limites que transversalizam territórios, delimitações de Estado, intervindo em múltiplas esferas de intervenção. As redes quando conexas tornaram-se populares em diferentes contextos: administração pública, ciência e empresas, avançando também para o campo das normatizações e influenciando na organização sócio política. O controle das redes tem gerado expectativas 
relacionadas à transparência e a segurança do seu funcionamento em todos os níveis, como os limites da utilização, o livre acesso, a produção e compartilhamento de dados estratégicos. Geralmente é compreendida o Big Data como a grande rede em que estão concentrados os dados digitais.

Quanto à disposição e o acesso desses dados é continuamente questionado a sua abertura pelos cidadãos. A promoção do acesso, portanto, está ligada à transparência dos processos. Em termos de quem é o produtor de dados, haverá conversas sobre transparência no governo, na pesquisa ou nas empresas, além da possibilidade do Estado tomar suas decisões a partir do cruzamento dessas informações. Análise que causa uma série de impactos conforme analisa Kerckhove:

\begin{abstract}
Portanto, a vigilância ubíqua e invisível, agora sustentada pelos algoritmos, não é outra coisa senão um incremento, uma sofisticação e refinamento da economia política no capitalismo digital. Assim, a biopolítica, que encontra hoje nos algoritmos, nos big data, seus maiores coadjuvantes, tem a ver com o poder que, regulado pela política científica, medicinal e jurídica, é exercido sobre a biologia, sobre a vida das populações que crescem cada vez mais, ocupando todos os espaços disponíveis sobre o globo. (KERCKHOVE, 2015, p.110).
\end{abstract}

Diante este fenômeno, a necessidade de diálogo para com os seus avanços. Partindo do preceito de que o modelo democrático consiste no fortalecimento da estrutura do Estado Democrático de Direito, sobretudo porque para que possamos compreender esse novo paradigma digital se faz necessário uma breve compreensão da sua dinâmica de funcionamento; para que, a partir daí, o campo jurídico enquanto ferramenta regulatória possa se posicionar na tentativa de assegurar ou retomar as suas concepções que foram cunhadas em um tempo cujos tais fenômenos não estavam postos, a exemplo de territorialidade, organização política, liberdade de expressão, privacidade. Também fica diante dos múltiplos questionamentos a seguinte inquietação: Quem controla o sistema digital, em especial o domínio do big data, e como proceder para limitar os impactos causados pelo surveillance?

A conceituação para big data exige que façamos uma imersão no campo das tecnologias da informação, já que remete não a delimitação de um objeto, mas sim ao plano virtual sob qual está assentado às conexões originárias na internet, ou seja, constitui um fenômeno em contínuo processo de expansão. É nesse espaço virtual que estão sedimentados o processo de construção contínua de uma pluralidade de dados e informações gerados por meio da interação de todos os sujeitos que partilham dessa rede. É também onde está registrado todas as interações emergentes 
das redes de compartilhamento, desde as relações econômicas, o plano das redes de convivência, os espaços de comunicação, o armazenamento de pesquisas cientificas e todas as atividades registradas no âmbito digital das vivências e conexões dos sujeitos modernos. Essa influência gera elementos objeto de poder e também contribuem para a formação não só de opinião ganhando caráter organizativo como observa YOUSSEF (2017):

Um novo conjunto de crenças e de valores está sendo forjado à medida que os modelos do novo poder se integram ao cotidiano das pessoas e aos sistemas operacionais das comunidades e sociedades. O poder não está apenas fluindo de forma diferente, pos as pessoas também o estão sentindo - e pensando sobre ele - de forma diversa. (YOYSSEF, 2017, p.60)

Isso significa que de todo esse complexo de informações e produções de informações terá a utilização e organização podendo ser utilizada para múltiplas finalidades. Daí emerge muitos dilemas no que tange o domínio, a possibilidade de manipulação e, sobretudo o controle e a exposição destes dados. A quem cabe a limitação de uma rede que extrapola os limites territoriais do Estado, criando constrangimentos a conceitos elementares do sistema jurídico como: soberania, privacidade, autodeterminação? Dilema que não somente está no âmbito público extrapolando inclusive a construção dos espaços privados. Tal problemática é objeto da seguinte análise:

No domínio do Big Data, os dados usados pelas organizações não estão necessariamente regulados por nenhum termo contratual. Associada a cada um de nós existe uma "nuvem de dados" desterritorializada gerada pelas nossas interações constantes com os serviços e dispositivos associados às tecnologias digitais da informação e comunicação. (DIAS, VIEIRA, 2013, p.173)

Ao buscar uma conceituação para o surveillance Menezes Neto (2016) o delimita como um grande sistema eletrônico capaz de articular a mais variada construção de dados sobre tudo o que é lançado no campo digital, no caso o big data, ou seja, traçando articulações. Nesse universo infinito de possibilidade de articulações de dados estamos diante o processo de indução para delinear características, afinidades, processos formativos, reforçando elementos identitários; que quando são possíveis de conectar acabam por gerar "bolhas sociais" capazes de serem induzidas para finalidades também desconhecidas. Por isso o termo extrapola os limites da tradução para vigilância, uma vez que por detrás de sua compreensão não está tão 
somente a violação da privacidade, mas a capacidade de gerar essas conexões pouco explicadas, por isso pode ser considerado:

[...] o conceito de suveillance ultrapassa os limites da concepção tradicional de vigilância, uma vez que permite trazer a tecnologia para dentro das relações sociais. Ao invés de ser uma terceira coisa que aumenta as capacidades vigilância, a tecnologia da informação passa a ser condição de possibilidade das interações humanas. Essa sutileza só se pode ser conseguida superando-se o conceito de vigilância. (MENEZES NETO, 2016, p.94)

Ao viabilizar que bolhas sociais cuja plataforma política não esteja comprometida para com os valores democráticos, que logrem alcançar espaços de poder político, acabam por bloquear o processo de manutenção do sistema democrático, quando são incapazes de primar pelo pluralismo ideológico, sobretudo porque ameaçam a existência dos grupos minoritários, como dispõe as garantias constitucionais de um sistema democrático. poder de transformação das mídias sociais:

Por outro lado, é inegável que nas mídias sociais, por exemplo, temos aproximações extraordinárias, ao ponto de falarmos de presenças conectadas e temos fenómenos de ajuntamentos maciços rápidos em que se verificam características específicas das massas, nomeadamente o alastramento rápido, como o fogo numa floresta, a intensidade crescente das reações por contágio do mata e esfola, e o direcionamento claro para um objetivo, nomeadamente a caça e o linchamento moral e político de uma figura pública. (FIDALGO, p.26, 2016)

Nesse contexto ganham força, ações e ideias incompatíveis para a concepção de uma democracia que seja capaz de reconhecer a integridades dos sujeitos que a compõe. A construção desses espaços viabiliza o surgimento de grupos que convergem para ideias extremistas que vão contra a perspectiva da diversidade da condição humana (ARENDT,1958), retomando pautas que até então pareciam superadas pelos ordenamentos jurídicos como a xenofobia, o racismo, a liberdade sexual. No campo político percebemos o fortalecimento de grupos extremistas (de ambos os polos ideológicos) e a retomada de populismos. No campo do domínio e da utilização dos dados também aparecem denúncias de violações de informações até então pertencentes ao Estado, cujos interesses eram limitados as suas próprias ações internas, violações que quando ganham contornos internacionais causam um enorme desconforto na comunidade global.

É possível notar que estamos diante um paradoxo. De um lado um sistema capaz de conectar múltiplos interesses, que poderiam fortalecer o plano democrático com o aperfeiçoamento do seu diálogo; do outro a ausência de segurança e o mínimo de privacidade 
necessária para o seu funcionamento. Aqui, o desafio de estabelecer uma grande incerteza uma vez que os rumos que estes movimentos podem tomar são imprevisíveis; sobretudo quando existe a pretensão de tomada do poder podendo inclusive desconsiderar o papel das instituições que constroem todo o complexo democrático.

\section{POR UMA REFLEXÃO GARANTISTA}

Na busca por possíveis soluções para evitar que a contínua violação dos dados e a interferência no processo de alienação não ganhe espaço, se faz necessário restabelecer a devoção à lei e aos princípios ordem constitucional evitando assim violações, de forma que possamos construir um positivismo garantista. Retoma-se a preocupação com a realidade de forma o sistema jurídico constitucional seja correlato com desenvolvimento do campo tecnológico. Por sua vez, surge o Garantismo Jurídico como interconexão por meio do paradigma constitucional e o compromisso para com a defesa real de um Estado Democrático de Direito. Uma vez sendo a defesa cuja amplitude e efetividades devem ser preservadas como condicionante para a existência e sobrevivência do próprio sistema jurídico.

Desse modo, as concepções teóricas das direito propostas por Luigi Ferrajoli trazidas por meio de uma leitura amplificada da sua obra Direito e Razão, nos vale para construção crítica, analítica, e, sobretudo por meio da sua perspectiva filosófica do Direito, serve de bússola norteadora. Sendo esta ferramenta imprescindível para compreensão de que se faz necessário limitar o exercício arbitrário do poder - seja ele a serviço dos interesses públicos ou privados a teoria garantista objetiva a real efetividade do ordenamento jurídico assegurando os direitos fundamentais já positivados uma vez que por vezes encontram-se ameaçados. Valendo-se desta análise ele conclui:

[...] a adequação de um sistema constitucional, sobretudo pelos mecanismos de invalidação e de reparações idôneos, de modo geral a assegurar efetividade aos direitos normalmente proclamados: uma Constituição pode ser muito avançada em vista dos princípios e direitos sancionados e não passar de um pedaço de papel, caso haja defeitos de técnicas coercitivas - ou seja, de garantias - que propiciem o controle e a neutralização do poder e do direito ilegítimo. (FERRAJOLI,2002, p.684) 
Todavia, a influência das concepções de Estado delineadas por Norberto Bobbio, compreendemos que sua teoria adquire caráter utópico por corresponder a uma análise crítica e até então não aplicada, porém o que não inviabiliza a necessidade de que seja perseguida como alternativa aos direitos em crise no que tange sua aplicabilidade.

É perceptível, neste cenário, a onipresença da Constituição, que ganha relevo em relação às leis, ou seja, ocorre a constitucionalização do direito. Além disso, ocorre a proliferação de princípios com destaque em relação às regras, com a consequente florescência da ponderação ao invés da subsunção e o incremento das competências do Poder Judiciário, com o aparecimento de certo ativismo judicial em detrimento da autonomia do legislador ordinário. Por fim, ocorre à centralidade dos direitos fundamentas e a preocupação com a efetivação dos direitos sociais. (NICOLLITT 2016, p.52).

A partir disso, importando da linguagem da ecologia o conceito de simbiose como processo de intercâmbio entre dois seres vivos, de forma que estes possuam uma associação na qual, ambos possam beneficiar-se mutualmente em uma relação que assegura a coexistência e uma relação de interdependência. Tal como essas relações a democracia digital deve encontrar no Garantismo Jurídico um importante aporte teórico e metodológico para consagrar e efetivar os bens jurídicos, princípios e a carga de direitos fundamentais pelas quais está envolto. Como desenvolve:

Partindo dessa máxima, o garantismo pressupõe, em primeiro lugar, epistemologicamente, a razão no direito, ou seja, uma crítica ao estado de direito, na medida em que se considera estado de direito garantista somente aquele Estado de Direito que esteja dotado de uma constituição rígida- modelo normativo de direito-, cujo princípio de legalidade - nesse caso estrita legalidade - que se configura a máxima de limite e vínculo ao poder. (COPETTI NETO, 2016, p.6)

Portanto o garantismo consiste em assegurar a efetividade do Estado Democrático de Direito partindo da insubordinação do mesmo perante qualquer que seja o tipo de poder estabelecido, independente de eles estarem atrelados ao campo privado, político ou econômico. Reconhece, portanto, o Constitucionalismo garantista e a real defesa dos direitos fundamentais, ou seja, uma teoria que é capaz de realizar uma análise crítica dos seus elementos de validade e efetividade. Ainda assim conclui que uma aproximação tal não é nem puramente "normativa" nem puramente "realista", a teoria que esta é hábil a fundar, precisamente, é uma teoria da divergência entre a normatividade e a realidade, entre direito válido e direito efetivo, um e outro vigente. (Ferrajoli, 2002).

A abordagem do seu aspecto externo ao direito dar-se-á a partir da compreensão de um direito cujas correntes doutrinárias divergiram durante a construção da Ciência do Direito. No 
plano da filosofia do direito, o garantismo requer um ônus de justificação externa com base nos bens e nos interesses dos quais a tutela ou a garantia constituem a finalidade. (Ferrajoli 2002). Isso remonta as dicotomias e relações existentes entre o direito e a moral, ou seja, regressa ao conflito entre o positivismo e o jusnaturalismo para posicionar-se defendendo a sua real separação, apontando também a relação necessária entre validade e justiça. Ao posicionar-se dessa forma reconhece a importância do debate distinguindo, portanto, os anseios das perspectivas individuais e coletivas pelas quais o direito está sujeito, fundamentados em direitos que podem conter tanto suas estruturas fundantes quanto sua razão/ justificativa. Tais elementares são mais bem compreendidas da seguinte forma:

\footnotetext{
Portanto, pode-se dizer, especificamente, que a dimensão formal da democracia é determinada por normas de reconhecimento do ordenamento constitucional, cujo conteúdo é revestido por normas de competência e que em acordo com essas normas de reconhecimento estabelece: quanto à democracia política: a) o princípio da representatividade política das funções de governo, que tem no exercício do direito político do voto a sua afirmação; b) o princípio da divisão de poderes; c) o princípio da separação entre funções de governo e funções de garantia; quanto à democracia civil: a) o princípio da autodeterminação do indivíduo, que tem no exercício do direito civil de autonomia a sua afirmação. Não é apenas método, mas também o é. (COPETTI NETO, VEIEIRA, 2017, p.163)
}

Diante de tantas questões, de forma que possamos acreditar nas bases fundantes do sistema jurídico, a teoria garantista nos remonta a necessidade de que a democracia deva ser levada a sério, uma vez que existem de um complexo aparato de garantias funcionais e institucionais, e é essa relação que faz o garantismo a outra face do sistema constitucional, vez que não se prende ao mero reconhecimento/ validade do aparato normativo, requer que dele exista uma real efetividade.

Ao resgatarmos o caso já analisado verificado que não é suficiente que o Estado acolha os avanços da tecnologia da informação, mas que também evite que as explorações das informações sejam limitadas quanto ao seu poder de condução ou segregação, impossibilitando o debate de um plano plural de concepções ideológicas e organizacionais uma vez que, não se pode creditar à apropriação individual de parcelas dos espaços de discussão democrática sem o reconhecimento da existência de um impacto negativo que viola outras garantias que estão ligadas a realização social, que por sua vez são invioláveis, inalienáveis, portanto indisponíveis. 


\section{CONSIDERAÇÕES FINAIS}

Por fim, a defesa de um sistema democrático por princípio faz uso do seu processo de edificação e a pluralidade de possibilidades que dele emergem e ao mesmo tempo demonstra sua fragilidade como elemento estratégico para o impedimento de que o próprio Estado tornese uma estrutura autoritária. Trata-se, em verdade, de um sistema bastante complexo e atual, na medida em que as múltiplas fragilidades estão presentes nos debates da atualidade, seja no âmbito da sua análise jurídica, como nas esferas do campo político, moral e filosófico, pois a democracia é construída justamente sobre a convergência desses sistemas, de maneira que seja sempre o caminho para barrar o surgimento de autoritarismos e as violações dos direitos conquistados.

Nota-se, por fim, que mediante as inovações e concepções de sociedade, ela também carece de atualizações. Observem que as contribuições advindas das transformações digitais não estabilizarão no tempo, uma vez que é um processo de contínua evolução, aprimorando o seu campo de influência e também construindo novas formas de convivência e interação entre os múltiplos sujeitos que dela fazem parte. Portanto, o que chama atenção, a princípio, é que a falta de controles reais do big data e as violações promovidas pelo surveillance, representam uma ameaça as "regras do jogo" democrático por não primarem pelo respeito à privacidade, além de promoverem um processo de indução e potencialização dos grupos que não reconhecem nos valores democráticos as soluções para a sociedade complexa.

Outrossim, corroborando com as informações supracitadas, que Luiggi Ferrajoli elabora em sua obra uma teoria exclusivamente voltada para o aprimoramento do Estado Democrático de Direito, aplicável quando reconhece no sistema jurídico normativo o melhor caminho para evitar a degeneração das conquistas históricas do campo democrático. A democracia, portanto, é o reconhecimento do direito, porque ela se constrói e se constitui a medida que os direitos fundamentais são assegurados e garantidos pelo próprio ordenamento jurídico ao sustentar as diretrizes de uma democracia constitucional. Ou seja, ela não está vinculada a mera formalidade do sistema democrático, mas assegura os seus elementos substanciais da democracia. 
Portanto se faz necessário a criação de alternativas para o problema da violação da democracia e dos direitos humanos, sobretudo da violação dos direitos fundamentais que estruturam o Estado Democrático de Direito, de forma que sejamos capazes de propor regulamentação deste campo digital, não deslegitimando a sua importância estrutural, mas, utilizando dessa tecnologia para aperfeiçoar o sistema democrático, tal como propõe a teoria do Estado Constitucional Garantista edificada por Ferrajoli.

\section{REFERÊNCIAS BIBLIOGRÁFICAS}

ALVES, Fernando B., OLIVEIRA, Guilherme F., DINIZ, Lucas T. M. et al. História, democracia e pensamento crítico na aplicação dos direitos fundamentais. Em Tempo. Marília, SP. v.15, p.35-54, 2016.

ARENDT, Hannah. A condição humana. Tradução de Roberto Raposo. 10.ed. Rio de Janeiro. Forense Universitária, 2003.

BOBBIO, N. O futuro da democracia. Tradução de Marco Aurélio Nogueira. 6. ed. Rio de Janeiro: Paz e Terra, 1997.

BONAVIDES, Paulo. Os poderes desarmados: à margem da Ciência Política, do Direito Constitucional e da História: figuras do passado e do presente. São Paulo: Malheiros, 2002.

BRASIL. Constituição da República Federativa do Brasil. Brasília, 1988.

COPETTI NETO, Alfredo. A Democracia Constitucional sob o olhar do garantismo jurídico. 1 ed .v.1. Empório do Direito. Florianópolis 2016.

COPETTI NETO, Alfredo. VIEIRA, Gustavo Oliveira, Direito e democracia sob a ótica constitucional: o fim ou o começo da história? Revista de Direito da Faculdade Guanambi, Guanambi, v.4, n.1. jan-jun. 2017.

ELY, John Hart. Democracia e desconfiança: uma teoria do controle judicial de constitucionalidade. Tradução: Juliana Lemos. São Paulo, Martins Fontes, 2010.

FERRAJOLI, Luigi. Direito e Razão. Teoria do Garantismo Penal. 3. ed. Rev. Amp. São Paulo: Revista dos Tribunais, 2002.

FIDALGO, António. Novas massas e novos poderes Massas na era da internet. In: LOPES, Maria Immacolata Vassallo de. KUNSCH, Margaria Maria Frohling. (Org). Comunicação Cultura e Mídias Sociais. São Paulo: ECA-USP, 2015.

KERCKHOVE, D., Ética de transparência na era do Big Data. In: LOPES, M.I.V.; KUNSCH, 
M.M.K. Comunicação, cultura e mídias sociais, São Paulo, ECA-USP, 2015. cap. 01. 13-36 MENEZES NETO, Elias Jacob de. Surveillance, democracia e direitos humanos: os limites do Estado na era do big data.2016.293f. Tese (Doutorado em Direito) Universidade do Vale do Rio dos Sinos, São Leopoldo, 2008.

WARAT, Luis Alberto. A Ciência Jurídica e seus dois maridos. 2. ed. Santa Cruz do Sul: EDUNISC, 2000, 200p.

YOUSSEF, Alê. Novo Poder: democracia e tecnologia. Belo Horizonte, Letramento, 2018.

Data de Submissão: 15/06/2020

Data de Aceite: 26/09/2020 